6. Nabovati E., Vakili-Arki H., Taherzadeh Z., et al. (2014). Drug-drug interactions in inpatient and outpatient settings in Iran: a systematic review of the literature. Journal of Pharmaceutical Sciences, 22(52):257-261.

7. Nogué $M$, Rambaud J, Fabre $\mathbf{S}$ et all. Longterm corticosteroid use and dietary advice: a qualitative analysis of the difficulties encountered by patient. BMC Health Serv Res. 2019 Apr 26,19(1): 255.

8. Oray M, Foster CS, Ebrahimiadib N. Long-term side effects of glucocorticoids. Expert Opinion on Drug Safety,January 2016,15(4): 457-65.

\title{
ĐÁNH GIÁ MộT SỐ YẾU TỐ LIÊN QUAN ĐẾN KIẾN THỨC VỀ DỰ PHÒNG ĐộT QUỴ NÃO CỦA NGƯỜI CAO TUỔI ĐANG ĐIỀU TRI ĐÁI THÁO ĐƯỜNG TẠI BỆNH VIỆN NộI TIẾT TRUNG ƯƠNG NĂM 2020
}

\section{TÓM TẮT}

Mục tiêu: Đánh giá một số yếu tố liên quan đến kiến thức về dự phòng đột quy não của người cao tuổi đang điều trị đái tháo đường. Đối tượng và phương pháp: Người cao tuổi đang điều trị đái tháo đường. Nghiên cứu mô tả cắt ngang. Kết quả: Tuổi, thời gian mắc bệnh, giới tính, nghề nghiệp, tiền sử gia đình có người mắc bệnh đột quy não không có mối liên quan với kiến thức về dự phòng bênh của đối tượng nghiên cứu với $p>0,05$. Trình độ học vấn, nguồn thông tin nhân được, chỉ số xét nghiêm (HbA1C, Cholesterol, Triglycerid) có mối liên quan với kiến thức dự phòng đôt quy não của đối tượng nghiên cứu với $p<0,05$. Kết luận: Trình độ học vấn, nguồn thông tin nhận, các chì số xét nghiệm có mối liên quan có ý nghĩa thống kê với kiến thức về dự phòng đột quy não của đối tương nghiên cứu

Tư khóa: Đái tháo đường, đột quỵ não, dự phòng đột quy não

\section{SUMMARY}

EVALUATION OF SOME FACTORS RELATED TO THE KNOWLEDGE OF PREVENTIVE STROKE

\section{ELDERLY ARE TREATED IN HOSPITAL} DIABETES ENDOCRINOLOGY 2020

Objectives: To evaluate a number of factors related to knowledge about brain stroke prevention among the elderly in treating diabetes. Subjects and method: The elderly are being treated for diabetes. Cross-sectional descriptive research. Results: Age, duration of illness, sex, occupation, family history of someone with cerebral stroke were not correlated with study subjects' knowledge of disease prevention with $p>0.05$. Educational attainment, received information sources, test indexes (HbA1C, Cholesterol, Triglycerid) were related to knowledge of brain stroke prevention

*Trường Đại học Điều dưỡng Nam Định Chịu trách nhiệm chính: Đỗ Thị Thu Hiền Email: thuhien80tnd@gmail.com Ngày nhân bài: 11/4/2021

Ngày phản biện khoa học: 8/5/2021

Ngày duyệt bài: 21/5/2021

\author{
Đỗ Thị Thu Hiền*, Trương Tuấn Anh* \\ Vũ Thị Dung*, Ngô Thị Thục Nhàn*
}

of study subjects with $p<0.05$. Conclusion: Education levels, sources of information received, and test indicators were statistically significant with the study subjects' knowledge of brain stroke prevention.

Keywords: Diabetes, brain stroke, prevention of brain stroke.

\section{I. ĐẶT VẤN ĐỀ}

Đột quy. não là một vấn đề sức khỏe trên toàn thế giới và là tác nhân chính gây ra bệnh tât, tử vong và tàn tât ở cả các nước phát triển và đang phát triển. Theo Trung tâm kiểm soát và phòng ngừa dịch bệnh, đột quy não là nguyên nhân hàng đâu gấy ra khuyết tật có thể phòng ngừa trên toàn thế giới [5]. Bệnh gây ra hậu quả nghiêm trọng đối với sức khỏe và chất lượng cuộc sống của những người sống sót sau đột quy não và những người chăm sóc họ [7]. Ở Việt Nam, theo thống kê của Bệnh viện Nội tiết Trung ương, năm 2012 tỷ lệ mắc đái tháo đường là $5,4 \%$ [1],[3].

Bệnh đái tháo đường cũng là một yếu tố nguy cơ có thể thay đổi đối với đột quy;; những người mắc bệnh đái tháo đường được cho là có nguy cơ đột quy. gấp 1,5 đến 3 lần so với những người không mắc bênh đái tháo đường. Tỷ lệ bênh đái tháo đường đang gia tăng ở nhiêuu nước đang phát triển một phân là do sự ưa thích ngày càng tăng đối với chế độ ăn uống không hợp lý.

Trong khi đó, theo thống kê cưa Liên đoàn Đái tháo đường quốc tế (IDF/International Diabetes Federation) năm 2015 Thế giới có khoảng 415 triệu người mắc bệnh đái tháo đường, trong đó $90 \%$ là đái tháo đường type II và hay gặp ở người cao tuổi. Tại Hoa Kỳ tỷ lệ mắc đái tháo đường ở độ tuổi 45-64 tuổi là $16,2 \%$ trong khi ở những người 60-79 tuổi là 25,9\% [8]. Kết quả nghiên cứu dịch tễ học đột quy. não ở khu vực Đông Á cho thấy tỷ lệ mắc đột quy. não ở những người trên 65 tuổi là 
5080/100.000 người [6].

Người bệnh không có kiến thức về các yếu tố nguy cơ của đột quy não ít tham gia vào các thực hành phòng ngừa đột quy não như kiểm soát huyết áp và thay đổi mô hình hành vi như cai thuốc lá và ăn chế độ ăn ít muối.

Để giúp nâng cao kiến thức của người bệnh đái tháo đường cao tuổi, chúng tôi tiến hành nghiên cứu với mục tiêu đánh giá một số yếu tố liên quan đến kiến thức về phòng ngừa đột quy. não của người bệnh cao tuổi bị đái tháo đường tại Bệnh viện Nội tiết Trung ương năm 2020

\section{II. ĐỐl TƯỢNG VÀ PHƯƠNG PHÁP NGHIÊN CỨU \\ 1. Đối tượng nghiên cứu}

- Người bệnh là NCT mắc bệnh ĐTĐ type II đến khám và điều trị tại Bệnh viện Nội tiết Trung ương.

- Tiêu chuẩn chọn: Người bệnh từ 60 tuổi trở lên; Người bệnh đến khám lại và điều trị bệnh ĐTĐ type II;

- Tiêu chuẩn loại: Người bệnh không có khả năng trả lời câu hỏi của phỏng vấn viên; Người bênh tình trang năng phải điều trị tích cực.

2. Thời gian, địa điểm nghiên cứu

- Địa điểm nghiên cứu: Bệnh viện Nội tiết Trung ương

- Thời gian thu thập số liệu: Từ tháng 12/2019 đến tháng 4/2020.

3. Thiết kế nghiên cứu: Nghiên cứu mô tả cắt ngang

\section{Phương pháp đo lường và đánh giá:}

- Xây dựng bộ công cự nghiên cứu: Bảng câu hỏi phỏng vấn, đánh giá độ tin cậy CronBach a đạt 0.866 , xin ý kiến chuyên gia về bộ câu hỏi phỏng vấn. Thu thập số liệu bằng cách phỏng vấn trực tiếp qua bộ công cụ. Số liệu được nhập, xử lý và phân tích bằng phần mềm SPSS 20.

- Tiêu chí đánh giá: Mỗi câu trả lợi đúng của người bệnh được 1 điểm, trả lời sai được 0 điểm. Tổng điểm càng cao thì kiến thức về phòng bệnh ĐQN càng cao. Sau đó chia làm 2 mức độ kiến thức về dự phòng bệnh ĐQN ở mức độ đạt khi $\geq 50 \%$ tổng số điểm và kiến thức mức độ không đạt khi < 50\% tổng số điểm.

\section{KẾT QUẢ NGHIÊN CứU}

Bảng 1. Mối liên quan giữa nguồn thông tin nhận được với kiến thức về dự phòng bệnh đột quy. não của đối tượng nghiên cứu

\begin{tabular}{|c|c|c|c|c|c|c|c|}
\hline \multirow{3}{*}{\multicolumn{2}{|c|}{ Đặc điểm }} & \multicolumn{4}{|c|}{ Kiến thức về dự phòng đột quy. não } & \multirow{3}{*}{$\begin{array}{c}\text { OR } \\
(95 \% \mathrm{CI})\end{array}$} & \multirow{3}{*}{ p } \\
\hline & & \multicolumn{2}{|c|}{ Không đạt } & \multicolumn{2}{|c|}{ Đạt } & & \\
\hline & & $\mathbf{n}$ & $\%$ & $\mathbf{n}$ & $\%$ & & \\
\hline \multirow{2}{*}{$\begin{array}{l}\text { Nguồn thông tin } \\
\text { về bệnh đột quy. } \\
\text { não nhận được }\end{array}$} & Không & 8 & 53,3 & 7 & 46,7 & \multirow{3}{*}{$\begin{array}{c}3,15 \\
(1,1-9,1)\end{array}$} & \multirow{3}{*}{0,037} \\
\hline & Có & 62 & 26,6 & 171 & 73,4 & & \\
\hline \multicolumn{2}{|l|}{ Tống } & 70 & 28,2 & 178 & 71,8 & & \\
\hline
\end{tabular}

Nhân xét: Nguồn thông tin về bênh ĐQN nhận được có mối liên quan với kiến thức về dự phòng ĐQN của đối tượng nghiên cứu với $\mathrm{p}<0,05 ; \mathrm{OR}=3,15 ; \mathrm{CI}: 1,1-9,1$. Người bệnh có nhận được nguồn thông tin về bệnh ĐQN có tỷ lệ kiến thức mức độ đạt cao hơn so với người bệnh khổng nhận được nguồn thông tin về bệnh.

Bảng 2. Mối liên quan giữa nghề nghiệp với kiến thức về dự phòng $Đ Q N$ của đổi tượng nghiên cứu

\begin{tabular}{|c|c|c|c|}
\hline \multicolumn{2}{|c|}{ Đặc điểm } & $\begin{array}{c}\text { Trung bình } \pm \\
\text { độ lệch chuẩn }\end{array}$ & $\begin{array}{c}\text { Phân } \\
\text { tích 2 } \\
\text { biến }\end{array}$ \\
\hline \multirow{2}{*}{ Nghề } & Làm ruộng & $24,88 \pm 2,03$ & \\
nghiệp & Công nhân & $27,50 \pm 2,12$ & $\mathrm{~F}=2,046$ \\
& Nô̂i trớ & $22,67 \pm 5,13$ & $\mathrm{p}=$ \\
& Viên chức & $25,05 \pm 5,34$ & 0,089 \\
& Nghề khác & $24,41 \pm 5,18$ & \\
\hline
\end{tabular}

Nhận xét: Nghề nghiệp không có mối liên quan với kiến thức về dự phòng ĐQN của người bệnh $(p>0,05)$.

Bảng 3. Mối liên quan giữ trình độ học vấn với $K T$ về $D P Ð Q N$ của $D T N C$

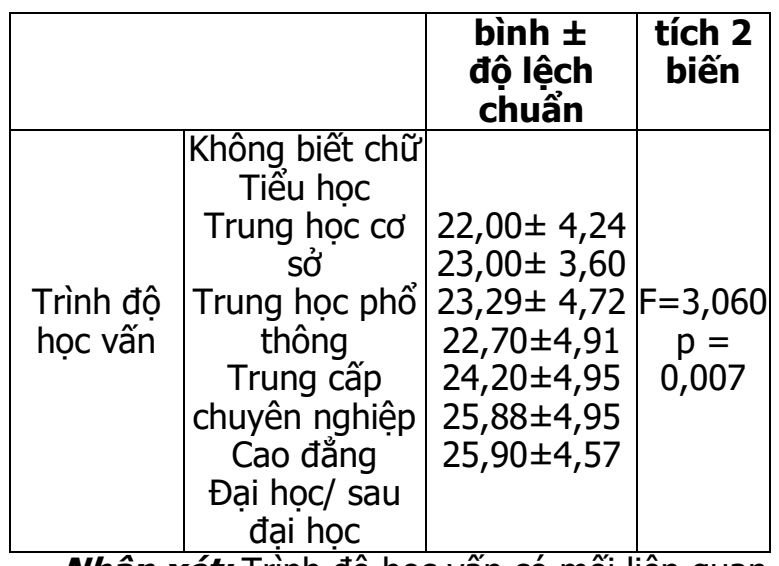

Nhânn xét: Trình độ học vấn có mối liên quan với kiển thức dự phòng ĐQN của đối tượng nghiên cứu với $p<0,05$. Điểm trung bình kiến 
thức phòng $Đ Q N$ của người bệnh có trình độ học vấn cao đắng/đại học/sau đại học cao hơn so với người bệnh trình độ học vấn thẩp.

Bảng 4. Mối liên quan giữa kêt quả $X N$ với kiến thức về DP ĐQN của ĐTNC

\begin{tabular}{|c|c|c|c|}
\hline \multicolumn{2}{|c|}{ Đặc điểm } & $\begin{array}{c}\text { Điếm trung } \\
\text { bình } \pm \text { Độ } \\
\text { lệch chuấn }\end{array}$ & $\begin{array}{c}\text { Phân tích } \\
\text { 2 biến }\end{array}$ \\
\hline \multirow{2}{*}{ HbA1C } & $\begin{array}{c}\text { Tốt } \\
26,12 \pm 3,83\end{array}$ & $\mathrm{~F}=91,62$ \\
& Chấp nhận & $26,34 \pm 2,98$ & $\mathrm{p}=0,000$ \\
& Kém & $18,62 \pm 4,65$ & \\
\hline \multirow{2}{*}{ Cholesterol } & Tốt & $26,85 \pm 2,76$ & $\mathrm{~F}=58,83$ \\
& Chấp nhận & $26,92 \pm 3,26$ & $\mathrm{p}=0,000$ \\
& Kém & $20,99 \pm 5,38$ & \\
\hline Triglycerid & Tốt & $26,95 \pm 2,54$ & $\mathrm{~F}=388,04$ \\
& Chấp nhận & $26,67 \pm 2,97$ & $\mathrm{p}=0,000$ \\
& Kém & $16,72 \pm 1,91$ & \\
\hline
\end{tabular}

Nhận xét: Kễt quả xét nghiệm $\mathrm{HbA1C}$, Cholesterol, Triglycerid có mối liên quan với kiến thức về dự phòng bệnh $Đ Q N$ của đối tượng nghiên cứu $(p<0,05)$. Người bệnh có $\mathrm{HbA1C}$, Cholesterol, Triglycerid mức độ tốt và chấp nhận có điểm trung bình kiến thức dự phòng bệnh tốt hơn so với người bệnh có $\mathrm{HbA1C}$, Cholesterol, Triglycerid mức độ kém.

\section{BÀN LUẦN}

1. Yếu tố nghề nghiệp không có mối liên quan đến kiến thức dự phòng đột quy. não ở người bệnh cao tuối có đái tháo đường. Nghề nghiệp là công việc của mỗi người phải thực hiện kéo dài trong cuộc sống, nó tác động đển con người trên nhiều khía cạnh như sức khỏe, tâm lý, kinh tế, gia đình của mỗi người. Làm việc trong các môi trường khác nhau, cường độ công việc, tính chất công việc khác nhau sẽ có những tác động khác nhau đến cơ thể. Công việc ít vận động sẽ tăng nguy cơ ĐQN cả hai giới nam và nữ và không phân biệt chủng tộc [4].

Nghề nghiệp không có mối liên quan với kiến thức về dự phòng ĐQN của người bệnh $(p>0,05)$ (bảng 3.17). Kết quả này khác với nghiên cứu Đinh Thị Yến có sự khác biệt về nhận thức các yếu tố nguy cơ ĐQN giữa các nhóm nghề nghiệp, sự khác biệt này có ý nghĩa thống kê với $\mathrm{p}<0,05$. Mark Kaddumukasa (2015) kiến thức về phòng ĐQN của người bệnh làm nghề nông thôn thấp hơn so với thành thị $(p=0,3131)$. Theo tác giả Lý Thị Kim Thương (2016) cho rằng người bệnh làm công nhân, viên chức có nhận thức về bệnh ĐQN tốt hơn so với các nghề khác với $\mathrm{p}<0,01$ là do những người làm công chức viên chức thường có trình độ học vấn cao, cơ hội tiếp cận với nhiều nguồn thông tin khác nhau tốt hơn và đi khám sức khỏe định kỳ thường xuyên hơn. Điều này không phù hợp với nghiên cứu chúng tôi [2].

2. Các yếu tố: Trình độ học vấn, tiếp cận nguồn thông tin, xét nghiệm cận lâm sàng có mối liên quan với kiến thức về dự phòng bệnh đột quy não của người bệnh cao tuổi có đái tháo đường. Trình độ học vấn có mối liên quan với kiến thức dự phòng ĐQN của đối tượng nghiên cứu với $p<0,05$. Điểm trung bình kiển thức phòng $Đ Q N$ của người bệnh có trình độ học vấn cao đẳng/đại học/sau đại học cao hởn so với người bệnh trình độ học vấn thấp. Trong đó, có sự khác biệt điểm trung bình kiến thức phòng bệnh ĐQN giữa nhóm có trình độ học vấn trung học phổ thông với nhóm cao đẳng ( $p<0,05)$, giữa nhóm trung học phổ thông với nhóm Đại học/sau đại học $(p<0,05)$. Kết quả này phù hợp với nghiên cứu Đinh Thị Yến những người tham gia có trình độ văn hóa từ tiểu học trở xuống có nhận thức không đạt về yếu tố nguy cơ ĐQN hơn nhiều so với người có trình độ văn hóa từ trung học trở lên. Sự khác biệt này là có ý nghĩa thống kề với $p<0,05$.

Nguiôn thông tin nhận được có mối liên quan với kiến thức về dự phòng ĐQN của đối tượng nghiên cứu với $\mathrm{p}<0,05 ; \mathrm{OR}=3,15 ; \mathrm{CI}: 1,1-9,1$. Người bệnh có nhận được nguồn thông tin về dự phòng bệnh ĐQN có tỷ lệ kiến thức mức độ đạt cao hơn so với người bệnh không nhận được nguồn thông tin về bệnh. Hỗ trợ từ người thân, bạn bè và các chuyên gia chăm sóc sức khỏe là cần thiết không chỉ để cung cấp thông tin hướng dẫn theo dõi các triệu chứng, thúc đẩy hành vi lành mạnh và hỗ trợ hữu hình để duy trì hành vi tự chăm sóc mà còn hỗ trợ người bệnh các hoạt động hàng ngày.

Kết quả xét nghiệm $\mathrm{HbA} 1 \mathrm{C}$, Cholesterol, Triglycerid có mối liên quan với kiến thức về dự phòng bệnh $\mathrm{DQN}$ của đối tượng nghiên cứu $(p<0,05)$. Người bệnh có HbA1C, Cholesterol, Triglycerid mức độ tốt và chấp nhận có điểm trung bình kiến thức dự phòng bệnh ĐQN tốt hơn so với người bệnh có HbA1C, Cholesterol, Triglycerid mức độ kém.

Phát hiện này nhấn mạnh sự cần thiết của các nhà hoạch định chính sách, quản lý nhân sự và các bên liên quan khác để biến việc giáo dục người bệnh (đặc biệt là những người mắc bệnh mãn tính) thành một thành phần thiết yếu của các quy trình quản lý ở tất cả các cấp cung cấp dịch vụ chăm sóc sức khỏe; và nó cần được bổ sung bằng giáo dục sức khỏe cộng đồng thông qua các phương tiện thông tin đại chúng.

Trên thế giới, tại các nước phát triển họ xây 
dựng hệ thống phòng, chống ĐQN rất hiệu quả bằng nhiều biện pháp như thành lập hội người có nguy cơ cao, tổ chức các đơn vị cấp cứu nhanh, giáo dục sức khỏe, thay đổi lối sống cho người có nguy cơ và đặc biệt là phổ biến giáo dục tới người dân những dấu hiệu cảnh báo sớm của ĐQN để khi có một trong các dấu hiệu nghi ngờ người bệnh có thể nhanh chóng nhận biết và nhờ sự can thiệp, hỗ trợ kịp thời từ người thân hoặc cán bộ y tế qua nhiêu kênh thông tin và biện pháp hỗ trợ khác nhau [1].

\section{KẾT LUÂN}

Trình độ học vấn có mối liên quan có ý nghĩa thống kê với kiến thức về dự phòng đột quy não của đối tượng nghiên cứu với $p<0,05$.

Nguồn thông tin nhận được về bệnh đột quy. não có mối liên quan có ý nghĩa thống kê với kiến thức về dự phòng đột quỵ. não của đối tượng nghiên cứu với $p<0,05$.

Các chỉ số xét nghiệm (HbA1C, Cholesterol, Triglycerid) có mối liên quan có ý nghĩa thống kê với kiến thức về dự phòng đột quỵ. não của đối tượng nghiên cứu với $p<0,05$.

Chưa tìm thấy có mối liên quan có ý nghĩa thống kê giữa tuổi, thời gian mắc bệnh, giới tính, nghề nghiệp, tiền sử gia đình có người mắc bệnh đột quy não với kiến thức về dự phòng bệnh của đối tượng nghiên cứu với p>0,05.

\section{TÀI LIÊU THAM KHẢO}

1. Bộ Y tế (2015). Quyết định phê duyệt Chiến lược quốc gia phòng, chống bệnh ung thứ, tim mạch, đái tháo đường, bênh phổi tắc nghẽn mạn tính, hen phế quản và các bênh không lây nhiếm khác, giai đoạn 2015 - 2025, Hà Nội.

2. Lê Thị Hương và cộng sự (2016). Tỷ lệ mắc đột quy tại 8 tỉnh thuộc 8 vùng sinh thái việt nam năm 2013-2014 và mộtt số yếu tố liên quan. Tạp chí nghiên cứu Y hoc, 104 (6), 1-6.

3. Trân Hồng Nhung (2014). Kiến thức thức hành phòng tai biến mạch máu não và một số yếu tố liên quan của người cao tuổi phường Đức Giang quận Long Biên Hà Nội, Đại hơc y tế công cộng.

4. Đinh Thi Yến (2017). Thay đổi nhân thức về đột quy não của người cao tuổi tại xã Giao Lac - Giao Thưy Nam Định sau can thiệp giáo dục sức khỏe. Luận văn thạc sĩ, trường Đại học Điều dưỡng Nam Định.

5. CDC (2014), Stroke Facts, Atlanta, USA, Centers for Disease Control and Prevention.

6. Cooper M.E., Jandeleit-Dahm K.A., Candido R. (2010). The Pathogenesis of Macrovascular Complications Including Atherosclerosis in Diabetes. Text book of Diabetes, Fourth Edition. Wiley Blackwell,637-649.

7. D. Mozaffarian \& et al. (2014). Heart disease and stroke statistics, a report from the American Heart Association, pp. 28-292.

8. Division of Diabetes Translation. and National Center for Chronic Disease Prevention and Health Promotion (2015). National Diabetes Statistics Report, 2014. Centers for Disease Control and Prevention, 1-12.

\title{
NGHIÊN CỨU CÁC CHỈ Số CHIỀU DÀI TRỤC NHÃN CẦ, Độ SÂU TIỀN PHÒNG, Độ DÀY GIÁC MẠC TRUNG TÂM VÀ Độ DÀY THỦY TINH THỂ TRÊN NGƯỜI VIÊTT NAM TỪ 46 ĐẾN 65 TUỔI
}

\author{
Nguyễn Thành Luân*, Nguyễn Thái Hà Dương**
}

\section{TÓM TẮT}

Mục tiêu: Xác định chỉ số chiều dài trục nhãn cầu, độ sâu tiền phòng, độ dày giác mạc trung tâm và độ dàythủy tinh thể trên người Việt Nam từ 46 đến 65 tuổi. Đánh giá một số yếu tố liển quan với các chỉ số nhân trắc của nhãn câu nêu trên. Đối tượng và phương pháp: Mô tả cắt ngang trên 195 người Việt Nam từ 46-65 tuổi bằng MáyIOLMaster700 tại bệnh viện Mắt Trung ương. Kết quả: 195 người với 94 nam $(48,2 \%)$ và 101 nữ $(51,7 \%)$, chiều dài trục nhãn câu:

\footnotetext{
*Trường Đại học Kỹ thuật Y tế Hải Dương

**Trướng Đại học Y Dược, ĐH Quốc gia HN

Chịu trách nghiệm chính: Nguyễn Thành Luân

Email: nguyenthanhluan27291@gmail.com

Ngày nhận bài: 15/4/2021

Ngày phản bienj khoa học: 3/5/2021

Ngày duyệt bài: 21/5/2021
}

$23,13 \pm 0,66 \mathrm{~mm}$, độ sâu tiền phòng:3,15 $\pm 0,36$ $\mathrm{mm}$, độ dày giác mạc trung tâm $529,15 \mu \mathrm{m} \pm 30,57$ $\mu \mathrm{m}$, đồ dày thủy tinh thể : 4,38 $\pm 0,42 \mathrm{~mm}$. Chiều dài trục nhãn câu, độ sâu tiền phòng, độ dày giác mạc trung tâm giảm theo tuổi và lớn hơn ở nam giới với $\mathrm{p}<0,05$. Độ dày thủy tinh thể tăng dân theo tuổi, không có sự khác biệt giữa nam giới và và nữ giới. Kết luận: Chiều dài trục nhãn cầu, độ sâu tiền phòng, độ dày giác mac trung tâm và độ dày thủy tinh thể là các chỉ số có giá trị trong chẩn đoán và điêu trị nhiều bệnh lý của nhãn cầu. Nghiên cứu xác định các chỉ số này trên người Việt Nam, đóng góp vào các chỉ số nhân trắc trên nhãn câu bình thường theo giới và các nhóm tuổi, làm tiêu chuẩn để so sánh với các trường hợp bệnh lý.

Tứ khóa: Chiêu dài trục nhãn câu, độ sâu tiền phòng, độ dày giác mạc, độ dày thủy tinh thể.

\section{SUMMARY \\ RESEARCH ON MEASUREMENTS OF OCULAR}

